\title{
Longitudinal Modelling of Body Mass Index from Birth to 14 Years
}

\author{
Paola Chivers $^{\mathrm{a}}$ Beth Hands ${ }^{\mathrm{b}, \mathrm{e}}$ Helen Parker $^{\mathrm{a}}$ Lawrence Beilin $^{\mathrm{c}}$ Garth Kendall ${ }^{\mathrm{b}, \mathrm{d}}$ \\ Max Bulsara ${ }^{\mathrm{e} f}$ \\ a School of Health Sciences, The University of Notre Dame Australia, Fremantle, \\ ${ }^{b}$ Centre for Child Health Research, Telethon Institute for Child Health Research, \\ 'Department of Medicine and Pharmacology, The University of Western Australia, \\ ${ }^{d}$ School for Nursing and Midwifery, Faculty of Health Sciences, Curtin University of Technology, Perth, \\ e Institute for Health and Rehabilitation Research, The University of Notre Dame Australia, Fremantle, \\ ${ }^{f}$ School of Population Health, The University of Western Australia, Perth, Australia
}

\section{Key Words}

Adiposity rebound - Adolescent - BMI - Children . Linear mixed models · Longitudinal survey · Obesity · Raine Study

\section{Summary}

Background: To examine the tracking of BMI from birth to age 14 years. Participants and Methods: Linear mixed model (LMM) analysis was used to model the trajectories of BMI ( $n=1,403$ ). Adiposity rebound was investigated for a subset of individuals ( $n=173$ ). Results: Adolescents who were overweight or obese at 14 years followed a different BMI trajectory from birth compared to those of normal weight. There was a difference between weight status groups for the timing of adiposity rebound $(p<0.001)$ and BMI at nadir $(p<$ 0.001 ). The LMM depicted a significant difference in rate of change of BMI over time for males and females $(p<$ 0.001 ), with female BMI increasing at a faster rate, and for weight status groups ( $p<0.005)$, with the obese cohort having the faster increase in BMI over time. BMI at birth was significantly lower for the normal weight cohort compared to the overweight $(p=0.029)$ and obese ( $p=0.019$ ) cohorts. Conclusion: This study introduces a powerful analytic tool, LMM, to model BMI and shows that weight status at 14 years is the result of a distinct path in earlier years. Compared to their normal weight peers, overweight and obese adolescents experience an earlier adiposity rebound, with a higher BMI at rebound.

\section{Introduction}

In Australia, unhealthy weight status has overtaken smoking as the major cause of preventable disease [1], supporting a similar trend in the United States [2]. Childhood obesity is associated with an increase in adverse health consequences in adulthood, with typically 'adult' health concerns now being diagnosed more often in children [3].

Infant birth weight is seen as a marker of intra-uterine health and well-being with influence on the child's developmental outcome. Controversy remains as to the role of infant birth weight on obesity when older. Some studies have reported a relationship between high birth weight and later obesity $[4,5]$, whereas low birth weight and rapid weight gain in infancy and childhood have also been shown [6], while others state that regardless of birth weight, rapid weight gain in the first 6 months is associated with obesity [7].

\section{Adiposity Rebound}

Adiposity rebound is thought to be an important marker for identifying the development of later obesity [8-11]. Adiposity rebound refers to the 2 nd rise in the BMI curve that usually occurs between the ages of 5-7 years, or more specifically the upward trend in BMI after its nadir [9-14]. This adiposity rebound has been argued to reflect upward BMI centile crossing, which at any age can predict later obesity [15]. Infancy sees the greatest height and weight growth rate, decreasing to a relatively constant growth rate during early to middle childhood $[7,16]$. Some argue that the timing of adiposity rebound in early childhood can accurately predict up to $30 \%$ of later obesity $[9-12,17]$. Rolland-Cachera and colleagues $[9,12]$ found that the occurrence of adiposity rebound at 3 years corresponded to obese individuals, while

\begin{tabular}{|c|c|}
\hline KARGER & (C) 2009 S. Karger GmbH, Freiburg \\
\hline $\begin{array}{l}\text { Fax +49 } 7614520714 \\
\text { Information@Karger.de } \\
\text { www.karger.com }\end{array}$ & $\begin{array}{l}\text { Accessible online at: } \\
\text { www.karger.com/ofa }\end{array}$ \\
\hline
\end{tabular}


adiposity rebound at 6 years corresponded to normal weight individuals.

In the last decade, biological and environmental factors that influence the timing of adiposity rebound have been investigated $[10,14]$. While parental obesity was strongly associated with earlier adiposity rebound $[10,14,17]$, dietary variables such as high protein intake were not [10]. It may be that early adiposity rebound is the result of some factors yet to be identified $[13,18,19]$, which may program later weight status $[13,20,21]$.

The purpose of this study was to develop a simple model of BMI from birth, using the alternative linear mixed model (LMM) for children separating differences for the IOTF (International Obesity Taskforce) cut-off categories of normal weight, overweight, or obese at 14 years, gender, and with particular interest in the adiposity rebound for each weight status group. Multilevel models are becoming popular in health and social sciences for the analysis of longitudinal data and provide an opportunity to investigate within-person and between-person change over time. The multilevel model for change is used to separate differences between individuals at baseline and changes over time within individuals. The model is a mathematical representation of population behaviour [22, 23], which enables correct modelling of correlated errors for repeated, continuous, and correlated observations [22], and has an underlying assumption that data are missing at random [24]. LMM has the advantage over repeated measures of ANOVA in that they are more flexible in fitting and testing covariance structures, permit individuals to have missing data points, and allow the inclusion of time-varying factors as well as the time measurement [24]. It is also the first time longitudinal BMI modelling in this cohort has been reported.

\section{Participants and Methods}

\section{Sample}

The Western Australian Pregnancy Cohort (Raine) Study enrolled mothers of 2,979 children in utero from antenatal clinics at the King Edward Memorial Hospital for Women (KEMH), Perth's primary specialist obstetric health care facility, and has followed 2,868 live-birth children. Women were enrolled into the project over 30 months from May 1989 to November 1991. Enrolment criteria included gestational age of 16-20 weeks, basic proficiency in English for informed consent, expectation of delivery at KEMH, and intention to remain in Western Australia. All mothers gave written informed consent, and the study was approved by the institutional ethics committees. The protocol for the original study has been previously reported describing the antenatal [25] and postnatal periods $[26,27]$.

The study has followed 2,868 live-born children who have been assessed at the follow-ups birth, 1, 2, 3, 6, 8, 10, and 14 years, with consent at each follow-up. The Raine Study families are broadly representative of the Western Australian population: $10.7 \%$ of parents being never married (vs. $9.8 \%$ ) and $7.5 \%$ of children being born $<37$ weeks (vs. $6.9 \%$ ), with a slight overrepresentation of children born $<2500 \mathrm{~g}(8.6 \mathrm{vs} .6 .5 \%)$. The Raine cohort is well-established and there is frequent contact between enrolled families and study organisers [28]. There has been attrition in sample sizes from each follow-up and among variables over time. Overall retention rates are high for each follow-up (92\% at 1 year, $74 \%$ at 2 years, $85 \%$ at 6 years, $82 \%$ at 8 and 10 years, and $79 \%$ at 14 years), with enthusiasm amongst participants to provide high quality information. In followup 2, funding limitations restricted the number of individuals assessed across physical measures, which impacted upon the sample size for BMI.

In this study, multiple birth, congenital abnormality, and pre-term birth (gestational age $<37$ weeks) cases were excluded from the sample. Only participants with a BMI at the survey year 14 were included, resulting in a total of 1,403 participants (674 (48\%) females, 729 (52\%) males) available for analysis from birth to 14 years. ANOVA tests were used to compare the weight status of the individuals selected for this study in the years 2,3 , 6,8 , and 10 to those excluded with no statistical difference at each survey year in proportions of normal, overweight, and obese. In survey year 2 , funding limitations restricted the collection of physical measures with only 400 individuals with valid BMI data. There was a slight selection bias in this sub-sample, which tended to have a higher proportion of professional fathers, high income families, and older mothers, but was similar to the retention trends seen across the follow-ups in the Raine Study. There were no statistical differences in gestational age, gender, or family structure. At 14 years, $73 \%(1,031)$ of adolescents were classified normal weight $(501$ females, 530 males), 19\% (263) overweight (127 females, 136 males), and $8 \%$ (109) obese (46 females, 63 males). BMI cut-off points of 25 and $30 \mathrm{~kg} / \mathrm{m}^{2}$, age, and gender adjusted for children were used to classify children as normal weight, overweight, or obese as defined by the IOTF criteria [29] at survey year 14. Gender-separated mean age, height, weight, BMI, and sample size at each follow-up is detailed in table 1.

\section{Anthropometric Measures}

Anthropometric measures were taken by a small group of extensively trained staff of the Telethon Institute for Child Health Research using strict protocols, with intra- and inter-rater reliability established at the beginning of each follow-up. The neonatal examination was conducted between 24 and $72 \mathrm{~h}$ following birth. Length was measured by 2 people using the Harpenden Neonatometer to the nearest $0.1 \mathrm{~cm}$. Newborns and infants (follow-up 1 year) were laid in supine position, with their head held by 1 person against a curved head plate in mid-line. The other person stretched the legs straight, knees held together, ankles flexed at right angles to the lower leg, moving the mobile plate to rest against the baby's feet. Weight was measured to the nearest $100 \mathrm{~g}$ using calibrated hospital scales at birth and a Wedderburn digital chair scales in follow-up 1 year.

In follow-ups 2 years and on, where appropriate, children were standing in the anatomical position, palms facing forward. Each area was measured at least twice in sequence with measures within $1 \mathrm{~cm}$. Unless stated, measures were taken at expiration. Height was measured using a Holtain stadiometer with shoes off, and heels, bottom, and head against the board. The chin was positioned to straighten the neck and the measure taken with a breath intake. Weight was measured to the nearest $100 \mathrm{~g}$ using a Wedderburn digital chair scales, with children wearing light clothing (running shorts and singlet top).

In each follow-up year, BMI was calculated from measured height and weight using the formula weight $(\mathrm{kg}) /$ height $(\mathrm{m})^{2}$, as defined by the IOTF criteria [29] at survey year 14. Adiposity rebound in this study was determined as the last minimum (nadir) BMI before the continuous increase in BMI over time [8]. For a subset of individuals with BMI at every followup $(\mathrm{n}=173)$, nadirs were calculated for each individual, with the average nadir for each weight status group then calculated. For the full sample (n $=1,403)$, the average BMI for each weight status group at each follow-up was calculated, and then the nadirs.

\section{Statistical Processes}

The statistical software SPSS version 15 and 17 (SPSS Inc., Chicago, IL, USA) was used for all statistical processes. Gender difference for mean height, weight, and BMI at each follow-up was analysed using independent t-tests. Mean height, weight, BMI, and adiposity rebound nadir for normal, overweight, and obese weight status were compared at each fol- 
Table 1. Cohort characteristics of the whole sample, males, and females at each survey wave (birth, 1, 2, 3, 6, 8, 10, and 14 years) for age, height, weight, and BMI

\begin{tabular}{|c|c|c|c|c|c|c|c|c|}
\hline \multirow[t]{2}{*}{ Variable } & \multicolumn{2}{|l|}{ Total } & \multicolumn{2}{|c|}{ Male } & \multicolumn{2}{|c|}{ Female } & \multicolumn{2}{|c|}{ Gender difference } \\
\hline & $\mathrm{n}$ & mean (SD) & $\mathrm{n}$ & mean $(\mathrm{SD})$ & $\mathrm{n}$ & mean $(\mathrm{SD})$ & $\mathrm{t}$ & $\mathrm{p}$ \\
\hline \multicolumn{9}{|l|}{ Birth } \\
\hline Gestational age, weeks & 1,403 & $39.31(1.30)$ & 729 & $39.34(1.31)$ & 674 & $39.28(1.28)$ & 0.80 & 0.421 \\
\hline Weight, kg & 1,402 & $3.44(0.47)$ & 728 & $3.50(0.47)$ & 674 & $3.37(0.46)$ & 5.26 & $<0.001$ \\
\hline Height, cm & 1,388 & $49.4(2.1)$ & 722 & $49.8(2.1)$ & 666 & $49.0(2.0)$ & 7.64 & $<0.001$ \\
\hline BMI, $\mathrm{kg} / \mathrm{m}^{2}$ & 1,388 & $14.0(1.4)$ & 722 & $14.1(1.3)$ & 666 & $14.0(1.4)$ & 0.48 & 0.631 \\
\hline \multicolumn{9}{|l|}{ Survey year 1} \\
\hline Age, months & 1,317 & $13.3(1.2)$ & 679 & $13.3(1.2)$ & 638 & $13.3(1.2)$ & -0.82 & 0.412 \\
\hline Weight, kg & 1,312 & $10.3(1.2)$ & 677 & $10.7(1.2)$ & 635 & $10.0(1.1)$ & 10.7 & $<0.001$ \\
\hline Height, cm & 1,305 & $77.6(3.1)$ & 673 & $78.3(3.1)$ & 632 & $76.9(2.9)$ & 8.28 & $<0.001$ \\
\hline BMI, $\mathrm{kg} / \mathrm{m}^{2}$ & 1,305 & $17.1(1.4)$ & 673 & $17.3(1.4)$ & 632 & $16.8(1.4)$ & 7.23 & $<0.001$ \\
\hline \multicolumn{9}{|l|}{ Survey year 2} \\
\hline Age, months & 449 & $25.6(1.7)$ & 238 & 25.7 (1.6) & 211 & $25.5(1.8)$ & 1.14 & 0.255 \\
\hline Weight, kg & 438 & $13.0(1.5)$ & 234 & $13.3(1.5)$ & 204 & $12.6(1.4)$ & 4.97 & $<0.001$ \\
\hline Height, $\mathrm{cm}$ & 401 & $90.1(3.7)$ & 208 & $90.6(3.6)$ & 193 & $89.5(3.7)$ & 2.97 & 0.003 \\
\hline $\mathrm{BMI}, \mathrm{kg} / \mathrm{m}^{2}$ & 400 & $16.0(1.3)$ & 207 & $16.2(1.3)$ & 193 & $15.7(1.21)$ & 3.82 & $<0.001$ \\
\hline \multicolumn{9}{|l|}{ Survey year 3} \\
\hline Age, months & 981 & $36.9(1.5)$ & 505 & $36.9(1.6)$ & 476 & $36.8(1.5)$ & 0.73 & 0.467 \\
\hline Weight, kg & 969 & $15.1(1.8)$ & 498 & $15.4(1.8)$ & 471 & $14.7(1.7)$ & 6.27 & $<0.001$ \\
\hline Height, cm & 964 & $96.4(3.8)$ & 494 & $97.0(3.9)$ & 470 & $95.6(3.5)$ & 5.91 & $<0.001$ \\
\hline BMI, $\mathrm{kg} / \mathrm{m}^{2}$ & 956 & $16.2(1.3)$ & 488 & $16.3(1.3)$ & 468 & $16.0(1.3)$ & 3.39 & 0.001 \\
\hline \multicolumn{9}{|l|}{ Survey year 6} \\
\hline Age, months & 1,327 & $70.5(2.3)$ & 690 & $70.6(2.4)$ & 637 & $70.5(2.2)$ & 0.33 & 0.741 \\
\hline Weight, kg & 1,261 & $21.4(3.3)$ & 656 & $21.7(3.4)$ & 605 & $21.1(3.2)$ & 3.24 & 0.001 \\
\hline Height, $\mathrm{cm}$ & 1,260 & $116.0(4.8)$ & 657 & $116.6(5.1)$ & 603 & $115.3(4.5)$ & 4.66 & $<0.001$ \\
\hline $\mathrm{BMI}, \mathrm{kg} / \mathrm{m}^{2}$ & 1,259 & $15.8(1.8)$ & 656 & $15.9(1.8)$ & 603 & $15.8(1.8)$ & 1.02 & 0.308 \\
\hline \multicolumn{9}{|l|}{ Survey year 8} \\
\hline Age, months & 1,272 & $96.7(4.1)$ & 651 & $96.8(4.1)$ & 621 & $96.6(4.1)$ & 0.98 & 0.327 \\
\hline Weight, kg & 1,271 & $28.2(5.6)$ & 652 & $28.4(5.7)$ & 619 & $27.9(5.5)$ & 1.67 & 0.095 \\
\hline Height, cm & 1,272 & $129.1(6.0)$ & 652 & $129.8(6.1)$ & 620 & $128.4(5.7)$ & 4.10 & $<0.001$ \\
\hline BMI, $\mathrm{kg} / \mathrm{m}^{2}$ & 1,271 & $16.8(2.5)$ & 652 & $16.8(2.5)$ & 619 & $16.8(2.5)$ & -0.34 & 0.738 \\
\hline \multicolumn{9}{|l|}{ Survey year 10} \\
\hline Age, months & 1,247 & $126.6(2.2)$ & 651 & $126.6(2.3)$ & 596 & $126.5(2.0)$ & 1.10 & 0.270 \\
\hline Weight, kg & 1,246 & $38.7(8.8)$ & 650 & $38.6(9.0)$ & 596 & $38.8(8.6)$ & -0.48 & 0.633 \\
\hline Height, cm & 1,247 & $143.7(6.6)$ & 651 & $143.7(6.7)$ & 596 & $143.7(6.4)$ & -0.12 & 0.904 \\
\hline BMI, $\mathrm{kg} / \mathrm{m}^{2}$ & 1,329 & $18.1(3.8)$ & 692 & $18.0(3.9)$ & 637 & $18.1(3.8)$ & -0.37 & 0.708 \\
\hline \multicolumn{9}{|l|}{ Survey year 14} \\
\hline Age, months & 1,403 & $168.3(2.3)$ & 729 & $168.2(2.4)$ & 674 & $168.3(2.3)$ & -0.54 & 0.592 \\
\hline Weight, kg & 1,403 & $58.0(13.3)$ & 729 & $58.8(14.3)$ & 674 & $57.1(12.1)$ & 2.40 & 0.017 \\
\hline Height, cm & 1,403 & $164.3(8.1)$ & 729 & $166.3(8.9)$ & 674 & $162.1(6.3)$ & 10.23 & $<0.001$ \\
\hline $\mathrm{BMI}, \mathrm{kg} / \mathrm{m}^{2}$ & 1,403 & $21.4(4.2)$ & 729 & $21.1(4.2)$ & 674 & $21.7(4.2)$ & -2.51 & 0.012 \\
\hline
\end{tabular}

low-up using ANOVA and Dunnett T3 post hoc tests. These statistical processes used the raw BMI data.

A LMM was performed to model the trajectory of BMI over time from birth to 14 years $(n=1,403)$. Fixed and random effects, interactions, and covariance structure were all investigated in the determination of the final model. A residual diagnostics plot was used to investigate the assumptions of normality and variance of the final proposed model.

BMI was treated as the dependent variable, with gender, age, gestational age, and weight status treated as factors. Time was used as a repeated measure. A non-linear transformation was applied to 'age' to determine the best model fit (based on Akaike's Information Criterion (AIC)). Polynomial fits were investigated to the 5 th order, but the quadratic (age squared) provided the best model fit (AIC) compared to higher form transformations. The linear term in the model did not account for variation in the early years nor describe the functional form, particularly the initial peak around age 1 year, or the nadir. Further investigation indicated the addition of a natural log function of age-improved model fit (AIC). This final model included age, age squared, 
Fig. 1. Predicted BMI trajectories from birth to 14 years, separated by weight categories normal weight, overweight, and obese (determined at 14 years using IOTF cut-offs), and gender. Mean age-adjusted BMI calculated for each survey wave is overlaid for each weight category and gender to demonstrate goodness of fit to the predicted BMI trajectory model.

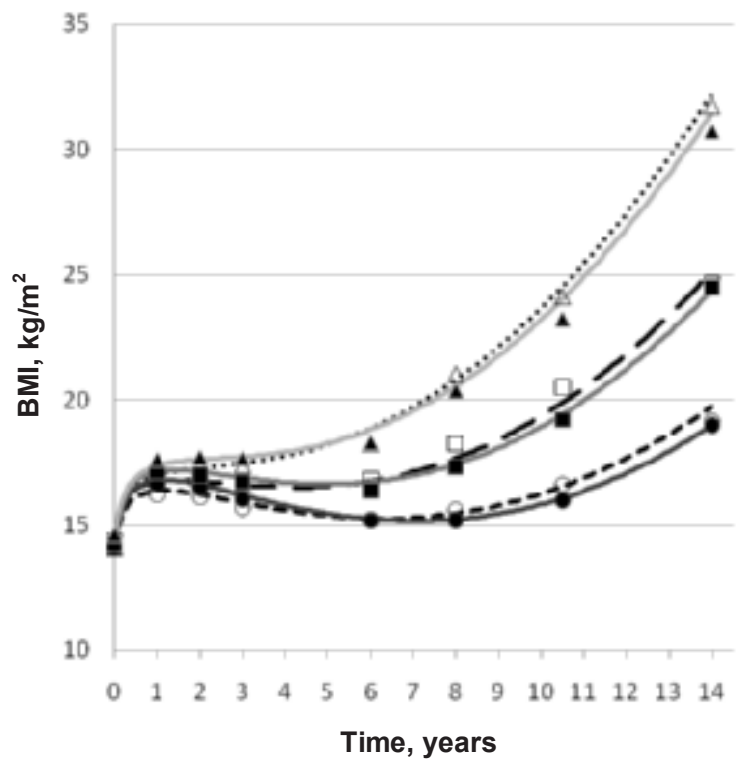

and the natural log of age and provided the best model fit (AIC) and model diagnostic results. Effects of age, gender, gestational age, and weight status (determined at age 14) were investigated as fixed effects in the model.

\section{Results}

There were significant gender differences in height and weight at every follow-up $(\mathrm{p}<0.05)$, with males taller and heavier than females, except for weight in year 8 and height and weight in year 10, where males and females were similar. Gender differences for BMI were significant at years 1, 2, 3, and 14 only $(\mathrm{p}<0.05)$, with males higher in BMI for years 1,2 , and 3 , while females were higher in BMI than males at year 14 . The BMI model (fig. 1) depicts this crossover point between 6 and 8 years of age. There were no gender differences in age at assessment, with survey year 8 having the largest age range.

BMI data were grouped according to gender and IOTF BMI weight status groups at year 14 . Using the weight status groupings at year 14, BMI group means were calculated at each follow-up (birth, 1, 2, 3, 6, 8, 10, and 14 years) for males and females, with results presented in table 2. The mean BMI trajectories from birth to 14 years for each weight category are plotted in figure 2. Evaluation of the height and weight data according to weight status and gender found that these differences were mostly attributable to changes in weight rather than height over time. Cross-sectional ANOVA tests supported this with the same post hoc results for BMI and weight, but not for height.

\section{Adiposity Rebound}

$\mathrm{BMI}$ at nadir and age at nadir were calculated for a subset of individuals with actual BMI at every follow-up $(\mathrm{n}=173)$ and are detailed in table 3 . There were significant weight status group differences for BMI at nadir and age at nadir $(\mathrm{p}<0.001)$, but no significant gender differences. In the subsample, adiposity rebound occurred for the normal weight group at 5.3 years, for the overweight group at 3.8 years, and for the obese group at 2.6 years. Post hoc analysis of weight status groups found a significant difference between BMI and age at nadir for females of the normal weight compared to overweight group, and normal weight compared to obese group. For males, there was only a significant difference in BMI at nadir between the normal weight and overweight and obese groups. There were no statistically significant differences between the overweight and obese groups. Adiposity rebound results were similar for the sub-sample $(\mathrm{n}=173)$ and full sample $(\mathrm{n}=1,403)$ and are shown pictorially for the full sample in figure 2. The BMI trajectory paths for each weight status are distinct in their different profiles, particularly in the timing of the peaks and troughs (fig. 2), and are based on the mean BMI for each weight status group and on the mean age at each follow-up.

Apart from the birth year, there were significant group differences in BMI means for males and females in all follow-ups $(\mathrm{p}<0.001)$. Post hoc analysis found a significant difference for males and females between the normal weight and overweight groups, between the normal weight and obese groups from follow-up 1 year onwards, between overweight and obese groups for males from follow-up 3 years onwards, and for females from follow-up 6 years onwards.

\section{BMI Longitudinal Modelling}

The final LMM (unstructured covariance) tested all possible interaction terms and found that there were no significant gender-weight category, age/age ${ }^{2} / \log$ Age-gestational age, gender-gestational age, or weight category-gestational age interactions, and these were removed from the final model. No 
Table 2. BMI summary statistics for each surdetermined for each individual in follow-up year 14 , separated for males and females vey year based on BMI IOTF weight categories

\begin{tabular}{|c|c|c|c|c|}
\hline \multirow[t]{3}{*}{ Survey wave } & \multicolumn{4}{|c|}{ BMI weight status determined at year 14} \\
\hline & \multicolumn{2}{|c|}{ male } & \multicolumn{2}{|c|}{ female } \\
\hline & $\mathrm{n}$ & mean $(\mathrm{SD}), \mathrm{kg} / \mathrm{m}^{2}$ & $\mathrm{n}$ & mean $(\mathrm{SD}), \mathrm{kg} / \mathrm{m}^{2}$ \\
\hline \multicolumn{5}{|l|}{ Birth } \\
\hline Normal weight & 526 & $14.0(1.3)$ & 494 & $14.0(1.4)$ \\
\hline Overweight & 133 & $14.1(1.5)$ & 127 & $14.3(1.3)$ \\
\hline Obese & 63 & $14.3(1.5)$ & 45 & $14.1(1.6)$ \\
\hline \multicolumn{5}{|l|}{ Year 1} \\
\hline Normal weight & 490 & $17.2(1.3)$ & 472 & $16.6(1.3)$ \\
\hline Overweight & 124 & $17.6(1.4)$ & 117 & $17.2(1.4)$ \\
\hline Obese & 59 & $18.0(1.4)$ & 43 & $17.5(1.1)$ \\
\hline \multicolumn{5}{|l|}{ Year 2} \\
\hline Normal weight & 153 & $15.9(1.1)$ & 151 & $15.5(1.1)$ \\
\hline Overweight & 40 & $16.9(1.8)$ & 29 & $16.3(1.2)$ \\
\hline Obese & 14 & $16.8(1.1)$ & 13 & $16.8(1.0)$ \\
\hline \multicolumn{5}{|l|}{ Year 3} \\
\hline Normal weight & 357 & $16.1(1.1)$ & 347 & $15.8(1.2)$ \\
\hline Overweight & 88 & $16.7(1.3)$ & 93 & $16.5(1.2)$ \\
\hline Obese & 43 & $17.6(1.5)$ & 28 & $17.2(1.8)$ \\
\hline \multicolumn{5}{|l|}{ Year 6} \\
\hline Normal weight & 476 & $15.3(1.2)$ & 449 & $15.3(1.2)$ \\
\hline Overweight & 122 & $16.7(1.7)$ & 114 & $16.7(1.6)$ \\
\hline Obese & 58 & $18.7(2.6)$ & 40 & $18.9(2.9)$ \\
\hline \multicolumn{5}{|l|}{ Year 8} \\
\hline Normal weight & 475 & $15.8(1.4)$ & 459 & $15.9(1.6)$ \\
\hline Overweight & 119 & $18.2(2.1)$ & 119 & $18.5(1.9)$ \\
\hline Obese & 58 & $21.7(3.3)$ & 41 & $21.8(3.9)$ \\
\hline \multicolumn{5}{|l|}{ Year 10} \\
\hline Normal weight & 506 & $16.8(2.5)$ & 473 & $16.9(2.6)$ \\
\hline Overweight & 127 & $19.9(3.8)$ & 121 & $20.3(3.6)$ \\
\hline Obese & 59 & $24.7(5.0)$ & 43 & $25.0(5.8)$ \\
\hline \multicolumn{5}{|l|}{ Year 14} \\
\hline Normal weight & 530 & $19.1(1.8)$ & 501 & $19.8(1.9)$ \\
\hline Overweight & 136 & $24.5(1.4)$ & 127 & $25.2(1.4)$ \\
\hline Obese & 63 & $31.3(3.3)$ & 46 & $32.8(3.7)$ \\
\hline
\end{tabular}

random effects were significant, and final model results are based on fixed effects only.

The final model can be described by the following equation:

BMI (predicted $)=$ intercept + weight status + gender + age (actual age $)$ + age $(\text { actual age })^{2}+\log$ Age $($ actual age +1$)+$ gestational age (actual gestational age $)+($ age $($ actual age $) \times$ gender $)+\left(\right.$ age $(\text { actual age })^{2} \times$ gen der $)+(\log$ Age $($ actual age +1$) \times$ gender $)+($ age $($ actual age $) \times$ weight status $)+\left(\right.$ age $(\text { actual age })^{2} \times$ weight status $)+(\log$ Age $($ actual age +1$)$ $\times$ weight status).

The model estimates and statistic results are depicted in table 4. By interchanging estimates into the equation, predicted BMI can be determined for any individual dependent upon their gender, weight status, age, and gestational age (fig. 1)

Even with pre-term children ( $<37$ weeks) removed from the sample, there was a significant gestational age effect $(\mathrm{p}<$
0.001), with every additional week in gestation resulting in an increase in BMI at birth. At birth (model intercept) there was a significant difference between the BMI of normal weight children compared to overweight $(\mathrm{p}=0.029)$ and obese $(\mathrm{p}$ $=0.019$ ) children, while the difference between overweight and obese was not significant. For example, for a female child born at 40 weeks gestation, their BMI at birth would be $14.2 \mathrm{~kg} / \mathrm{m}^{2}$ if normal weight at age 14 compared to $14.4 \mathrm{~kg} / \mathrm{m}^{2}$ if overweight at age 14 , or $14.5 \mathrm{~kg} / \mathrm{m}^{2}$ if obese at age 14 . There was no significant gender effect between male and female BMI at birth. However, females increased their BMI at a faster rate than males $(\mathrm{p}<0.001)$, which accounts for the overlap seen in the trajectory by 8 years. The increase in BMI over time was statistically different for each weight status group, with the obese cohort showing the largest rate of increase 
Fig. 2. Mean BMI over time based on BMI IOTF weight category as determined at survey year $14(n=1,403)$. Adiposity rebound in this study was determined as the minimum BMI value.

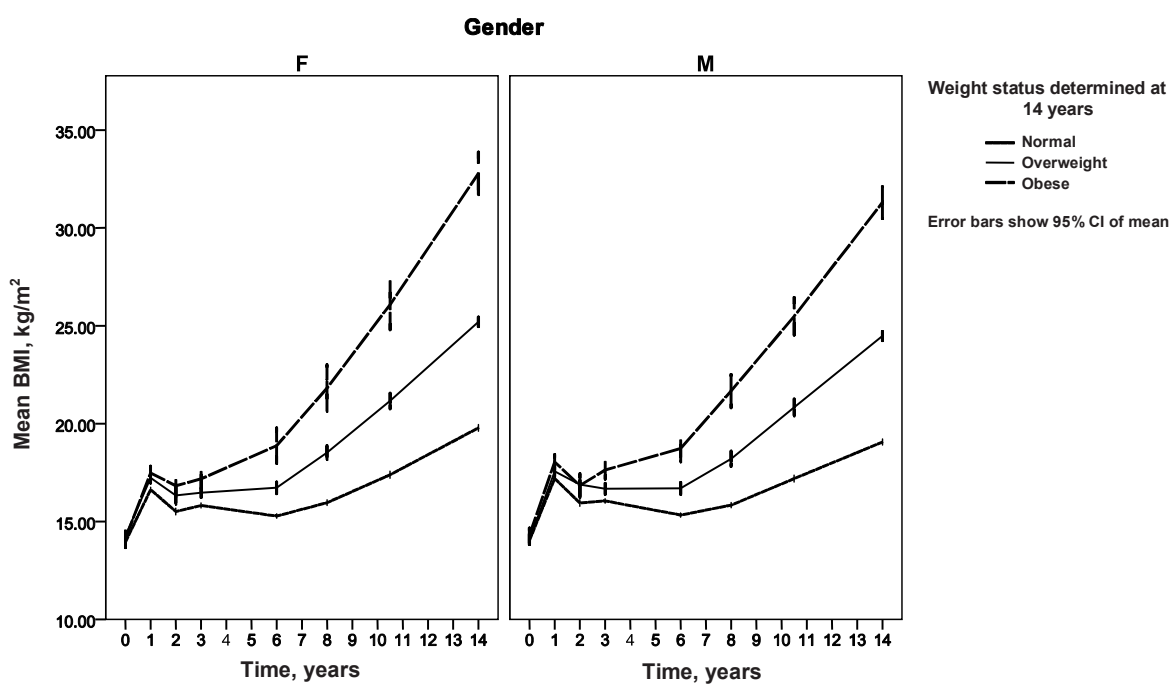

\begin{tabular}{|c|c|c|c|c|c|c|}
\hline \multirow{2}{*}{$\begin{array}{l}\text { BMI weight status } \\
\text { determined at } \\
\text { year } 14\end{array}$} & \multicolumn{2}{|c|}{ Male } & \multicolumn{2}{|c|}{ Female } & \multicolumn{2}{|c|}{ Total } \\
\hline & $\mathrm{n}$ & mean (SD) & $\mathrm{n}$ & mean $(\mathrm{SD})$ & $\mathrm{n}$ & mean $(\mathrm{SD})$ \\
\hline \multicolumn{7}{|l|}{ BMI nadir ${ }^{a}, \mathrm{~kg} / \mathrm{m}^{2}$} \\
\hline Normal weight & 71 & $15.1(0.9)^{\mathrm{b}}$ & 61 & $14.9(1.0)^{\mathrm{b}}$ & 132 & $15.0(1.0)^{\mathrm{b}}$ \\
\hline Overweight & 19 & $16.7(1.3)$ & 13 & $16.1(1.2)^{\mathrm{c}}$ & 32 & $16.4(1.3)^{\mathrm{c}}$ \\
\hline Obese & 5 & $16.3(1.2)$ & 4 & $16.6(0.3)$ & 9 & $16.4(0.9)$ \\
\hline \multicolumn{7}{|l|}{ Age nadir ${ }^{a}$, years } \\
\hline Normal weight & 71 & $5.4(2.0)$ & 61 & $5.1(2.3)^{\mathrm{b}}$ & 132 & $5.3(2.2)^{\mathrm{b}}$ \\
\hline Overweight & 19 & $4.2(2.4)$ & 13 & $3.2(1.9)^{\mathrm{c}}$ & 32 & $3.8(2.2)^{\mathrm{c}}$ \\
\hline Obese & 5 & $3.1(1.7)$ & 4 & $2.0(0.7)$ & 9 & $2.6(1.4)$ \\
\hline
\end{tabular}

${ }^{a}$ Significant difference in ANOVA between groups test $\mathrm{p}<0.005$.

${ }^{\mathrm{b}}$ Significant difference between normal weight and overweight groups $\mathrm{p}<0.05$.

'Significant difference between normal weight and obese weight groups $\mathrm{p}<0.005$. $(\mathrm{p}<0.001)$, as shown in figure 1 . The modelled BMI trajectories, with an overlay of mean age-adjusted BMI at each follow-up, depicted in figure 1 indicate a relative good fit, which is supported by the residual diagnostics which followed an approximate normal distribution, although there was a slight deviation at the positive tail.

\section{Discussion}

The BMI trajectories followed a distinct pathway from birth to 14 years for individuals within different weight categories. As suggested by others $[9,13]$, the timing of the adiposity rebound can be seen as a marker for later obesity. Our data shows more clearly than Rolland-Cachera's figures $[8,9]$ the distinct and significantly different pathways followed by the 3 weight status groups for both the raw means and modelled data. A major limitation for determining adiposity rebound is the absence of data at years 4 and 5 as well as the smaller sample at year 2, and this was reflected in the lack of statistical difference between the overweight and obese weight status groups only, although pictorially a difference is shown. We also found a statistical difference in BMI at nadir, with the normal weight group having a lower BMI at rebound compared to the overweight and obese groups.

The limitation in the number of data points up to age 6 and in particular between age 3 and 6 years may play a significant part in the adiposity rebound age and BMI nadirs reported. Although the ages for the obese and normal weight groups appear clear, those for the overweight group are not. The STRIP study reported by Lagström and colleagues [30] collected annual measurements until age 13 and reported adiposity rebound at 4.3 years for overweight boys and 3.8 years for overweight girls. In reviewing our BMI trajectory plots (fig. 2), it is likely that there may have been a lower BMI point somewhere between assessments at 3 and 6 years of age. Irrespective, it is clear that the overweight adiposity rebound occurs at some point at, or after, 3 years and before 6 years in 
Table 4. Final BMI linear mixed model: estimates of fixed effects for parameters

\begin{tabular}{|c|c|c|c|}
\hline Parameter & BMI estimate & Standard error & Significance \\
\hline Intercept & 8.334684 & 0.762569 & $<0.001$ \\
\hline \multicolumn{4}{|l|}{ Weight status } \\
\hline Obese group & 0.314924 & 0.134407 & 0.019 \\
\hline Overweight group & 0.201214 & 0.092172 & 0.029 \\
\hline Normal weight group & 0 & 0 & \\
\hline \multicolumn{4}{|l|}{ Gender } \\
\hline Female & -0.038381 & 0.071336 & 0.591 \\
\hline Male & 0 & 0 & \\
\hline Age & -0.121952 & 0.002623 & $<0.001$ \\
\hline $\mathrm{Age}^{2}$ & 0.000614 & 0.000011 & $<0.001$ \\
\hline LogAge & 1.546032 & 0.033056 & $<0.001$ \\
\hline Gestational age & 0.146582 & 0.019332 & $<0.001$ \\
\hline \multicolumn{4}{|l|}{ Age $\times$ gender } \\
\hline Female interaction & 0.015887 & 0.003451 & $<0.001$ \\
\hline Male interaction & 0 & 0 & \\
\hline \multicolumn{4}{|l|}{$\mathrm{Age}^{2} \times$ gender } \\
\hline Female interaction & -0.000027 & 0.000015 & 0.076 \\
\hline Male interaction & 0 & 0 & \\
\hline \multicolumn{4}{|l|}{ LogAge $\times$ gender } \\
\hline Female interaction & -0.217211 & 0.043482 & $<0.001$ \\
\hline Male interaction & 0 & 0 & \\
\hline \multicolumn{4}{|l|}{ Age $\times$ weight status } \\
\hline Obese interaction & 0.028256 & 0.006479 & $<0.001$ \\
\hline Overweight interaction & 0.005560 & 0.004472 & 0.214 \\
\hline Normal weight interaction & 0 & 0 & \\
\hline \multicolumn{4}{|l|}{$\mathrm{Age}^{2} \times$ weight status } \\
\hline Obese interaction & 0.000269 & 0.000028 & $<0.001$ \\
\hline Overweight interaction & 0.000144 & 0.000019 & $<0.001$ \\
\hline Normal weight interaction & 0 & 0 & \\
\hline \multicolumn{4}{|l|}{ LogAge $\times$ weight status } \\
\hline Obese interaction & -0.036766 & 0.081960 & 0.654 \\
\hline Overweight interaction & 0.030509 & 0.056258 & 0.588 \\
\hline Normal weight interaction & 0 & 0 & \\
\hline
\end{tabular}

this cohort. This is well before that of the normal group and those originally reported by Rolland-Cachera and colleagues [8], yet similar to more recent studies [9, 30].

Our finding on adiposity rebound supports others who found that the earlier the occurrence of the adiposity rebound, the higher the BMI with age $[9,12,30]$. However, unlike Rolland-Cachera and colleagues [12], we have pre-classified our children into weight status at age 14 and then calculated their average adiposity rebound in the earlier years. This difference in methodology may account for our finding that the higher the BMI at year 1, the earlier the age of rebound. Cole [15] argues that the timing of adiposity rebound is reflective of children with high centile BMI or upward centile crossing. Like others, we believe that the occurrence of the earlier adiposity rebound is a marker for early determinants or mechanisms of obesity $[13,15,18,19]$. These include environmental, behavioural, and individual factors (such as breastfeeding, diet, physical activity, and genetics) that may program later weight status $[13,20,21]$. To date, however, the value of identifying the timing of adiposity rebound for use in a clinical setting is yet to be confirmed [11].

Although our findings on adiposity rebound are similar to others $[9,30]$, the meaning of the distinct peaks and troughs in $\mathrm{BMI}$ in relation to child behaviour is as yet unclear. Analysis of the height and weight data found that the changes observed in BMI were principally related to changes in weight and not in height. This can be accounted for by height and weight growth rates that occur during childhood [7]. While height trajectories were very similar for all 3 weight categories, the overweight and obese groups were gaining weight at a faster 
rate than their normal weight counterparts. This was most pronounced by 3 years of age, although statistically significant from age 1 . Adiposity rebound for the obese group occurred at around 2 years, the same as the beginning of the 2 nd critical period for adiposity proposed by Botton and colleagues [7].

The LMM analysis found that the trajectories of BMI were different between males and females as well as for each weight category (fig. 1). This difference was in both the rate of change over time (acceleration) and their BMI at birth. The interaction effects showed that the pathways for males and females were significantly different within the weight categories, with females slightly leaner than males when young and with a crossover in later childhood/early adolescence. The obese group increased their BMI over time at a faster rate, and this difference began from birth. Our results include more frequent collection points and have a larger sample, use the powerful LMM analytic tool, and support results reported by Blair and colleagues [4] for their New Zealand cohort. Like them, we believe that the pre-school years are the critical time period for the development of obesogenic behaviours.

The overlay of mean age-adjusted BMI at each follow-up on the modelled BMI trajectories provided an overview of goodness of fit of our proposed model (fig. 1), with residual diagnostics supporting this. The tight clustering of mean data points in the first few years again highlights the need for greater in-depth analysis of this important period with more frequent data collection points, perhaps at 3-monthly intervals.

It is therefore apparent that the increased rate in weight gain accounts for later adiposity in this cohort, however, the underlying causes of the accelerated weight gain are unclear. Our proposed model of BMI over this time period provides an opportunity for the examination of growth patterns and the impact of other, yet untested, covariates which may assist in the understanding of the development of obesity [31]. Parents often observe children undergoing increased hunger and appetite as well as weight gain, followed by decreased appetite and height growth or episodes of spurt and lag [32]. One explanation may be that established food behaviours do not follow the pendulum return of decreased appetite during growth for the overweight and obese groups. Physical and social aspects of the home environment may also influence food choices based on types of food available, parent food behaviours, and feeding practices [33]. There may also be a developmental switch triggered by the environment that is present or absent in the overweight and obese [4, 34]. In addition, the level of physical activity and sedentary pastimes could be important. Dubois and Girard [18] concluded that influences of behavioural and social factors were critical to the possible onset of obesity in the early pre-school years. Regardless of cause, rapid weight gain after age 1 is associated with adverse health effects [34], and this critical period of development requires intensive investigation in regards to obesity. Our proposed model provides an opportunity to test the influence of such factors on the trajectory of BMI, specifically to weight status at 14 years.

\section{Strengths and Limitations}

The sample described was not drawn randomly, but enrolled in utero from the major Women's Hospital in Perth, Western Australia, and therefore the findings may not be truly representative, with a slight selection bias in this study's sample. There was an expected attrition rate, with variation across follow-ups and among measured variables, although overall participant numbers remained high.

Specific to this study, data collection at follow-ups is in years, with the time point an average age at that assessment. In some follow-ups there was a large range of ages for collection of data. This is particularly significant in respect to the mean BMI trajectories presented and the calculation of adiposity rebound, although the clear distinction in time points still provides a valid assessment of the difference between the weight status categories. The Raine Study did not collect data in years 4 and 5, and these are important years for adiposity rebound, although this seemed relevant to the overweight and obese group distinctions only. Notably, we believe our data underestimate the occurrence of adiposity rebound because of this limitation. All other results presented have been calculated using actual age of the child. Lastly, accurate puberty data for this study was not available across gender; therefore, no control for maturity was able to be made in the later follow-ups.

The strength of this study is the unique mixed modelling used which accounts for correlated errors normally associated with repeated, continuous, and correlated observations as well as an ability to handle missing data, uses a simple growth model approach, and is more flexible than traditional repeated measures ANOVA. The LMM permits the evaluation of age as a covariate, rather than predetermined averaged time points (follow-ups), increasing the validity of the model. The large sample, even with attrition, provides for more accurate distinctions to be made among gender and weight categories. The longitudinal nature of the cohort, from birth to year 14, provides an opportunity to examine early pathways of weight status, in particular a re-examination of the adiposity rebound. This modelling approach provides an opportunity to test mechanisms that might drive accelerated and early increases in BMI.

\section{Conclusion}

A simple model of BMI trajectory was proposed using LMM which shows that from birth to 6 years is a key developmental period for adiposity. For children who are obese at 14 years, the critical period was earlier, i.e. between birth and 2 years, than for normal and overweight children. The adiposity rebound occurred earlier among the obese cohort. These findings indicate that obesity determinants may be individual, behavioural, or environmental, but most likely multi-factorial, probably gender-specific, with each factor contributing 
its own level of risk to the individual. This powerful analytical approach provides a mechanism to further investigate the contribution of possible determinants to adiposity during this period.

To conclude, this study introduces an alternate analytic tool, LMM, to model BMI trajectories, the first time reported in this cohort. Results from this approach support the importance of the early years (birth to age 6) in the development of adolescent obesity and provides an opportunity for further research into the interplay of individual, behavioural, and environmental factors which lead to a healthy or unhealthy weight.

\section{Acknowledgements}

We are extremely grateful to all the families who took part in this study and the whole Raine Study team, which includes data collectors, cohort managers, data managers, clerical staff, research scientists, and volunteers. The Western Australian Pregnancy Cohort Study is funded by the Raine Medical Research Foundation at the University of Western Australia and by a grant from Healthway Western Australia and is supported by the Telethon Institute for Child Health Research (NHMRC Program Grant).

\section{Disclosure}

The authors declared no conflict of interest.

\section{References}

1 Australian Institute of Health and Welfare: Australia's health 2006. AIHW Cat. No. AUS 73. Canberra, Australian Institute of Health and Welfare, 2006.

2 Haslam DW, James WPT: Obesity. Lancet 2005; 366: 1197-1209.

3 World Health Organisation: Obesity and overweight. Fact Sheet No. 311. 2006. www.who.int/mediacentre/factsheets/fs311/en/print.html.

4 Blair NJ, Thompson JM, Black PN, Becroft DM, Clark PM, Han DY, Robinson E, Waldie KE, Wild CJ, Mitchell EA: Risk factors for obesity in 7-yearold European children: the Auckland Birthweight Collaborative Study. Arch Dis Child 2007;92:866871.

5 National Health and Medical Research Council: Clinical practice guidelines for the management of overweight and obesity in children and adolescents. Canberra, Commonwealth of Australia, 2003. www. health.gov.au/internet/main/publishing.nsf/Content/ 893169B10DD846FCCA256F190003BADA/\$File/ children.pdf.

6 Sloboda DM, Hart R, Doherty DA, Pennell CE, Hickey M: Age at menarche: influences of prenatal and postnatal growth. J Clin Endocrinol Metab 2007; 92:46-50.

7 Botton J, Heude B, Maccario J, Ducimetière P, Charles MA; FLVS Study Group: Postnatal weight and height growth velocities at different ages between birth and $5 \mathrm{y}$ and body composition in adolescent boys and girls. Am J Clin Nutr 2008;87: 1760-1768.

-8 Rolland-Cachera MF, Deheeger M, Bellisle F, Sempé M, Guilloud-Bataille M, Patois E: Adiposity rebound in children: a simple indicator for predicting obesity. Am J Clin Nutr 1984;39:129-135.

$\checkmark$ Rolland-Cachera MF, Deheeger M, Maillot M, Bellisle F: Early adiposity rebound: causes and consequences for obesity in children and adults. Int J Obes Relat Metab Disord 2006;30:S11-S17.

10 Dorosty AR, Emmett PM, Cowin IS, Reilly JJ: Factors associated with early adiposity rebound. Pediatrics 2000;105:1115-1118

11 Dietz WH: 'Adiposity rebound': reality or epiphenomenon? Lancet 2000;356:2027.
12 Rolland-Cachera MF, Deheeger M, Guilloud-Bataille M, Avons P, Patois E, Sempé M: Tracking the development of adiposity from one month of age to adulthood. Ann Hum Biol 1987;14:219-229.

13 Small L, Anderson D, Melnyk BM: Prevention and early treatment of overweight and obesity in young children: a critical review and appraisal of the evidence. Pediatr Nurs 2007;33:149.

14 Williams S, Dickson N: Early growth, menarche, and adiposity rebound. Lancet 2002;359:580.

15 Cole TJ: Children grow and horses race: is the adiposity rebound a critical period for later obesity? Pediatrics 2004;4:6-13.

16 Sun SS: Growth and development; in Goran MI, Sothern M (eds): Handbook of Pediatric Obesity: Etiology, Pathophysiology, and Prevention. Boca Raton, FL, Taylor and Francis Group, 2006, pp 19-34.

17 Whitaker RC, Pepe MS, Wright JA, Seidel KD, Dietz WH: Early adiposity rebound and the risk of adult obesity. Pediatrics 1998;101:462.

18 Dubois L, Girard M: Early determinants of overweight at 4.5 years in a population-based longitudinal study. Int J Obes (Lond) 2006;30:610-617.

19 Rolland-Cachera MF, Deheeger M, Bellisle F: Increasing prevalence of obesity among 18 -year-old males in Sweden: evidence for early determinants. Acta Paediatr 1999;88:365-367.

20 Hallal PC, Wells JC, Reichert FF, Anselmi L, Victora CG: Early determinants of physical activity in adolescence: prospective birth cohort study. BMJ 2006:332:1002-1006.

21 Skinner JD, Bounds W, Carruth BR, Morris M, Ziegler P: Predictors of children's body mass index: a longitudinal study of diet and growth in children aged 2-8 y. Int J Obes Relat Metab Disord 2004;28: 476-482.

22 Garson GD: Linear Mixed Models. 2008. www2. chass.ncsu.edu/garson/pa765/multilevel.htm.

23 Singer JD, Willet JB: Applied Longitudinal Data Analysis. Modeling Change and Event Occurrence. New York, Oxford University Press, 2003.

24 West BT, Welch KB, Galecki AT: Linear Mixed Models. A Practical Guide Using Statistical Software. London, Taylor and Francis Group, 2007.
25 Newnham JP, Evans SF, Michael CA, Stanley FJ Landau LI: Effects of frequent ultrasound during pregnancy: a randomised controlled trial. Lancet 1993;342:887-891.

26 Oddy WH, Holt PG, Sly PD, Read AW, Landau LI, Stanley FJ, Kendall GE, Burton PR: Association between breast feeding and asthma in 6 year old children: findings of a prospective birth cohort study. BMJ 1999;319:815-819.

27 Joseph-Bowen J, de Klerk NH, Firth MJ, Kendall GE, Holt PG, Sly PD: Lung function, bronchial responsiveness, and asthma in a community cohort of 6-year-old children. Am J Respir Crit Care Med 2004;169:850-854.

$28 \mathrm{Li} \mathrm{C}$, Kendall GE, Henderson S, Downie J, Landsborough L, Oddy WH: Maternal psychosocial wellbeing in pregnancy and breastfeeding duration. Acta Paediatr 2008;97:221-225.

29 Cole TJ, Bellizzi MC, Flegal KM, Dietz WH: Establishing a standard definition for child overweight and obesity worldwide: international survey. BMJ 2000;320:1-6.

30 Lagström H, Hakanen M, Niinikoski H, Viikari J, Rönnemaa T, Saarinen M, Pahkala K, Simell O: Growth patterns and obesity development in overweight or normal-weight 13-year-old adolescents: the STRIP study. Pediatrics 2008;122:e876-883.

31 Heude B, Kettaneh A, de Lauzon Guillain B, Lommez A, Borys JM, Ducimetière P, Charles MA: Growth curves of anthropometric indices in a general population of French children and comparison with reference data. Eur J Clin Nutr 2006;60:1430 1436.

32 Wilson RS: Twins: genetic influence on growth; in Malina RM, Bouchard C (eds): Sport and Human Genetics. Champaign, IL, Human Kinetics, 1986, pp 1-21.

33 Bryant MJ, Ward DS, Hales D, Vaughn A, Tabak RG, Stevens J: Reliability and validity of the Health Home Survey: a tool to measure factors within homes hypothesized to relate to overweight in children. Int J Behav Nutr Phys Act 2008;5:23.

34 Eriksson JG, Forsen T, Tuomilehto J, Osmond C, Barker DJP: Early growth and coronary heart disease in later life: longitudinal study. BMJ 2001;322: 949-953. 